\title{
Influence of Mitochondria Origin on Fruit Quality in a Citrus Cybrid
}

\author{
Jean-Baptiste Bassene, ${ }^{\dagger}$ Liliane Berti, ${ }^{\ddagger}$ Elodie Carcouet,${ }^{\S}$ \\ Claudie Dhuique-Mayer, ${ }^{\prime \prime}$ Anne-Laure Fanciullino, ${ }^{\dagger}$ Jean Bouffin, ${ }^{\dagger}$ \\ Patrick Ollitrault, ${ }^{\dagger}$ AND Yann Froelicher $*{ }^{*}$
}

Centre de Coopération Internationale en Recherche Agronomique pour le Développement (CIRAD), UPR Multiplication végétative, F-20230 San Giuliano, France, Université de Corse, UMR CNRS 6134, Laboratoire Biochimie et Biologie Moléculaire du Végétal, Quartier Grossetti, BP 52, 20250 Corte, France, Institut National de Recherche Agronomique (INRA), UR GEQA, San Giuliano, F-20230 San Giuliano, France, and CIRAD, UMR QUALISUD, F-34398 Montpellier Cedex 5, France

\begin{abstract}
Sugar, organic acid, and carotenoid are the most important indicators of fruit taste and nutritional and organoleptic quality. These components were studied on fruit pulp of the cybrid between Willow leaf mandarin (Citrus deliciosa Ten.) and Eureka lemon [Citrus limon (L.) Burm.] and the two parents. The cybrid possessed nuclear and chloroplast genomes of Eureka lemon plus mitochondria from Willow leaf mandarin. The impact of new mitochondria on fruit quality was studied during the mature period. Levels of organic acids were slightly higher in the cybrid fruit pulp than in Eureka lemon. No significant difference in sugar and carotenoid content was observed between the cybrid and the lemon. Results confirm that the main genetic information for the biosynthesis of sugars, organic acids, and carotenoids is contained in the nucleus. In Citrus, cybridization can be used as a strategy to breed specific traits associated with mitochondrial genomes, such as male sterility, without affecting the main organoleptic and nutritional qualities.
\end{abstract}

KEYWORDS: Citrus; diploid somatic hybrid; cybrid; sugars; organic acids; carotenoids; fruit quality

\section{INTRODUCTION}

Nutritional and organoleptic fruit qualities are currently very important objectives for plant breeders. For citrus cultivars, fruit quality must be managed at the same time as other characters, such as seedlessness, productivity, harvesting period, and sometimes tolerance to diseases (1). Moreover sexual breeding of citrus is a difficult task mostly because of the highly heterozygous genetic structure of modern species, including sweet orange, grapefruit, and lemons, that are the result of interspecific hybridization (2). For these species, breeding methods are needed that do not affect the complex genetic structures that define the pomological and organoleptic characteristics of the species (3).

Somatic cybridization has been proposed as a potential approach to breed citrus cultivars for specific traits, such as seedlessness or tolerance traits, as well as to slightly modify phenological or quality traits for diversification of the cultivar. Special interest is paid to transfer cytoplasmic male sterility $(4,5)$, and Guo et al. (6) tried to transfer the

* To whom correspondence should be addressed. Telephone: +33(0)495595911. Fax: +33(0)495595937. E-mail: froelicher@ cirad.fr.

${ }^{\dagger}$ UPR Multiplication végétative, CIRAD.

\#niversité de Corse.

$\S$ INRA.

"UMR QUALISUD, CIRAD. cytoplasmic male sterility of the satsuma mandarin to seedy citrus cultivars. A cybrid is a cytoplasmic hybrid possessing the nucleus of one species and the mitochondria and/or chloroplast of another species. In citrus, cybrids could be obtained by asymmetric fusion between irradiated protoplast with a destroyed nucleus and an iodoacetate-treated protoplast $(7,8)$, but most citrus cybrids have been obtained by symmetric hybridization $(9-11)$. Recently, the production of an alloplasmic hybrid via cytoplast-protoplast fusion has been developed in citrus (12). In the case of somatic hybridization between a mesophyll protoplast and an embryogenic callus protoplast, the cybrid systematically contained mitochondria from the embryogenic callus $(13,14)$.

In plant breeding, male sterility and tolerance traits determined cytoplasmically have been the most common objective of such strategies (15-19). A cybrid with new mitochondrial genomes could also be used to improve breeding systems in terms of flower morphology and attractiveness to insects $(19-22)$.

Citrus cybrids are a good model to study the impact of nucleo-cytoplasmic interactions on internal fruit quality at the basic research level. It has been shown that cybridization can have an impact on aroma. Fanciullino et al. (23) found that, for volatile compounds of leaves, the cybrids were very close to their nucleus-giving parent; however, some nucleo-cytoplasmic 
interactions occurred, such as the synthesis of more monoterpene alcohols and sesquiterpene in the kumquat and clementine cybrid.

The acidity of the citrus fruit results directly from the citric acid cycle. The mitochondria are the site of biosynthesis in the citric acid cycle even if the genes involved are located in the genome of the nucleus. Carotenoid biosynthesis is located in the plast or the chloroplast (24), and all of the genes are located in the nucleus $(25,26)$. The biosynthesis of sugars is much more complex because the chloroplast and mitochondria play an important rule in photosynthesis and respiration, respectively.

Assessing the impact of the nucleo-cytoplasmic interaction on citrus fruit quality would allow us to estimate (i) how cybridization could be used to breed traits, such as seedlessness or resistance, without modifying organoleptic and nutritional quality or, (ii) in contrast, how it could enable modification of quality characters to better fit consumer requirements as a strategy for diversification of cultivars.

One cybrid between Willow leaf mandarin (Citrus deliciosa Ten.) and Eureka lemon [Citrus limon (L.) Burm.] has been produced by symmetric fusion by CIRAD (27). This cybrid is of great interest because the two parents display very strong differentiation in fruit quality. Willow leaf mandarin is an orange sweet fruit, while Eureka lemon is a yellow acidic fruit. The phylogenetic origin of the cytoplasm from the two parents is different. Willow leaf mandarin belongs to $C$. reticulata, while the origin of the lemon cytoplasm is $C$. maxima (pummelo taxon) $(2,28)$. The aim of our study was to determine the effects of this new nucleo-mitochondria interaction on the biosynthesis of sugars, acids, and carotenoids, which are widely recognized to be important components of fruit and juice quality (29).

\section{MATERIALS AND METHODS}

Plant Materials. The study was conducted on fruits of Willow leaf mandarin (Citrus deliciosa Ten.), Eureka lemon [Citrus limon (L.) Burm.], and their cybrid called WLM + EUR (Citrus deliciosa Ten.) and [Citrus limon (L.) Burm.]. WLM + EUR was produced by symmetric protoplast fusion (27). The two parents and WLM + EUR mature budwood were all grafted onto volkameriana rootstock (Citrus limonia Obs.) and randomly planted in the same field at the Station de Recherche Agronomiques (INRA/CIRAD) in San Giuliano (Corsica, France) in 2002.

Genetic Characterization. Genetic characterization was performed according to previously published methods. Ploidy level was analyzed by flow cytometry (30). All molecular markers were studied by polyacrylamide gel electrophoresis (PAGE) in sequencing gels with silver staining. Molecular characterization of the nuclear genome was performed using 26 polymorphic simple sequence repeat (SSR) markers (31). The chloroplast genome was characterized using four chloroplastic SSR markers $(32,33)$. The origin of the mitochondrial genome was studied using four universal polymerase chain reaction (PCR) primers described by Mouhaya et al. (28) (manuscript submitted).

Fruit Sampling for Analysis of Acidity and Sugars. Fruits were harvested at 15 day intervals on three trees per variety at stage III of fruit development (34) from December to February. Four fruits were collected from each tree at each sampling. Fruits were individually peeled, and their pulp was frozen in liquid nitrogen and stored at -140 ${ }^{\circ} \mathrm{C}$. The frozen fruit pulp was then lyophilized and powdered before analysis. The extractions for high-performance liquid chromatography (HPLC) analysis were made with the different samples from the three trees, for each genotype.

Titratable Acidity. A total of $100 \mathrm{mg}$ of powdered pulp was suspended in $5 \mathrm{~mL}$ of bidistilled water. Titratable acidity was determined by titration to $\mathrm{pH} 8.1$ with $0.1 \mathrm{~mol} \mathrm{~L}^{-1} \mathrm{NaOH}$, using an

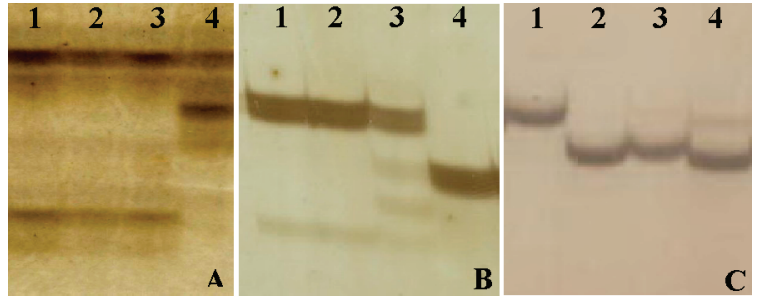

Figure 1. Analysis of genetic constitution of WLM + EUR: (A) nuclear SSR marker mCrCIR07E12, (B) chloroplastic SSR marker ntcp9, and (C) mitochondrial primer rrn5/rrn18-1. Lane 1, Eureka lemon; lanes 2 and 3, two clones of WLM + EUR; and lane 4, Willow leaf mandarin.

automatic Mettler titrator DL25 (Mettler-Toledo, France). Titratable acidity was expressed as milliequivalents per gram of fresh pulp (meq $\mathrm{g}^{-1} \mathrm{fp}$ ).

Analysis of Organic Acids and Sugars. A total of $100 \mathrm{mg}$ of powdered pulp were dissolved in $5 \mathrm{~mL}$ of bidistilled water and centrifuged at $160 \mathrm{~g}$ for $20 \mathrm{~min}$. The supernatant was filtered through $25 \mathrm{~mm}$ syringe filters, $0.45 \mu \mathrm{m}$ cellulose acetate membranes (VWR). Organic acids and sugars were analyzed with an analytical HPLC unit (Perkin-Elmer, Series 200, France) as previously described by Albertini et al. (35).

Data was acquired using TotalChrom software for Windows version 6.2 (Perkin-Elmer Instruments, Shelton, CT). Concentrations of organic acids and sugars were expressed as milligrams per gram of fresh pulp (mg $\mathrm{g}^{-1} \mathrm{fp}$ ).

Carotenoid Analysis. Carotenoid analysis was performed on juice sacs of fruits of Willow leaf mandarin, Eureka lemon, and WLM + EUR harvested at full maturity, 225 days after anthesis (DAA). Carotenoids were analyzed by HPLC using an Agilent 1100 system (Massy, France). Carotenoids were extracted, identified, and quantified as described by Dhuique-Mayer et al. (36) and Fanciullino et al. (37). The concentration of each carotenoid was expressed as $\mathrm{mg} \mathrm{L}^{-1}$.

Statistical Analysis. Data were subjected to one-way analysis of variance (ANOVA) using the GLM procedure of SAS (SAS Institute, Inc., 1989) to analyze the quantitative differences between the three genotypes.

\section{RESULTS}

Genetic Characterization. Flow cytometry analysis showed that WLM + EUR is diploid $(2 n=18)$. Molecular markers were chosen to display polymorphism between the parents and consequently allowed us to identify the genomic origin of our cybrid. Analysis of nuclear DNA by 26 SSR markers revealed that the cybrid only possessed bands from Eureka lemon (Figure 1A). No recombination or deletion was observed. Chloroplast SSR enabled the two parents to be clearly distinguished and revealed that WLM + EUR conserved the chloroplast from Eureka lemon (Figure 1B). Mitochondria markers showed that the cybrid had bands from Willow leaf (Figure 1C). The cybrid combined the nucleus and chloroplasts from Eureka lemon with mitochondria from Willow leaf mandarin.

Titratable Acidity. Titratable acidity was analyzed during the mature stage (180-260 DAA). The cybrid and Eureka lemon had the most acidic fruits, and the titratable acidity remained constant during this period with an average of 0.94 and 0.80 meq $\mathrm{g}^{-1} \mathrm{fp}$, respectively. The cybrid was slightly more acidic than Eureka lemon. Willow leaf was less acidic, with an average of $0.11 \mathrm{meq}^{-1} \mathrm{fp}$.

Organic Acid Contents at the Mature Fruit Stage. Seven organic acids were detected and identified in pulp of the three genotypes. The dominant acid was citric acid, representing an average of $89.86 \%$ of the total organic acids for Eureka lemon, $89.73 \%$ for the cybrid, and $72.27 \%$ for Willow leaf mandarin. Malic acid was the second highest, with an average of $18 \%$ of the total organic acids in Willow leaf and 9\% in Eureka lemon 

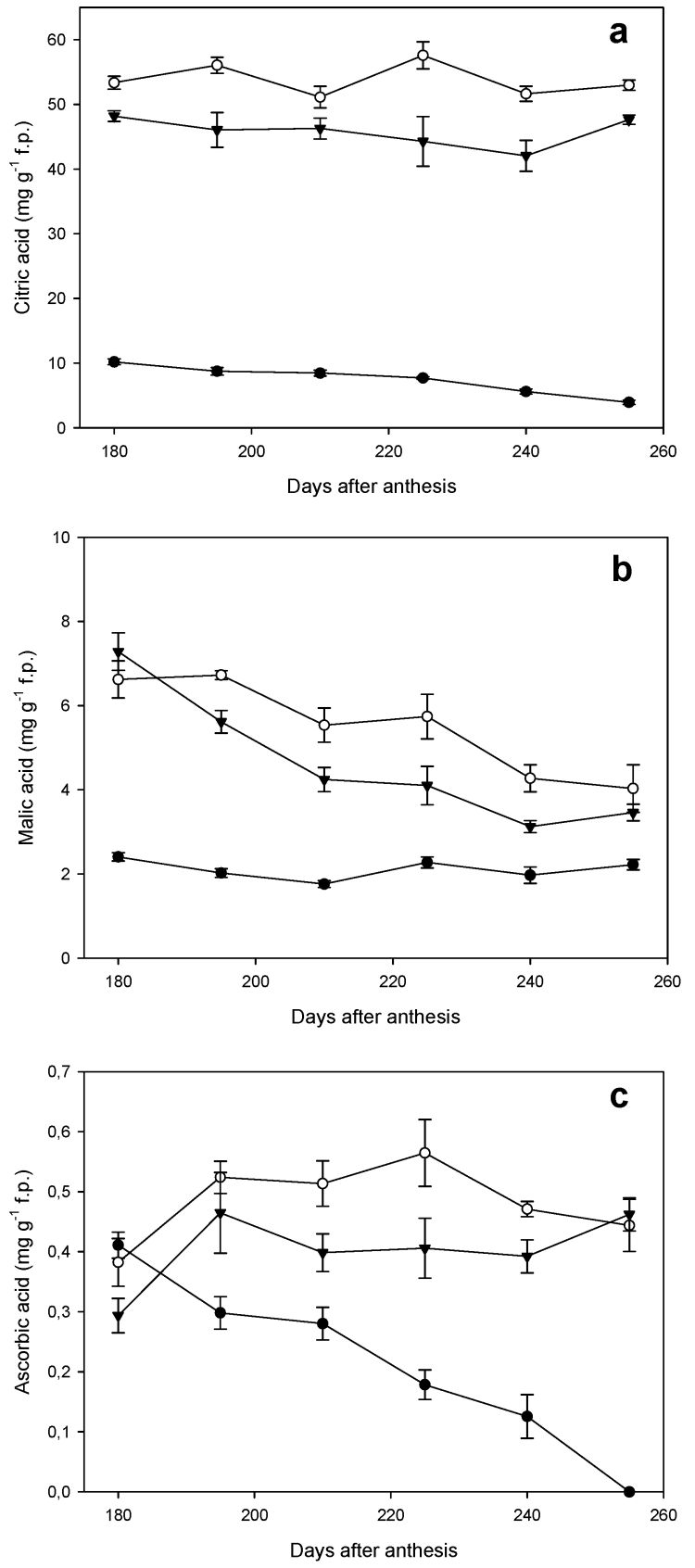

$\longrightarrow$ Willow leaf $-\mathrm{O}-\mathrm{WLM}+\mathrm{EUR} \rightarrow \boldsymbol{-}$. Lemon

Figure 2. Organic acid levels in fruit pulp during the mature stage of

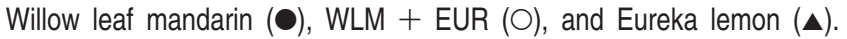
Each point on the graph shows the mean and standard error of three biological replicates.

and the cybrid. Other acids, such as oxalic, ascorbic, succinic, tartaric, and quinic acid, were present in very low amounts compared to the two dominant acids.

Citric acid contents in the cybrid and Eureka lemon were constant throughout the mature stage, whereas it decreased in Willow leaf mandarin. The cybrid displayed the highest amounts of citric acid, $53 \mathrm{mg} \mathrm{g}^{-1} \mathrm{fp}$ on average, still close to its lemon parent, $45 \mathrm{mg} \mathrm{g}^{-1} \mathrm{fp}$ on average (Figure 2a). Willow leaf had very low amounts of citric acid, $7 \mathrm{mg} \mathrm{g}^{-1}$ fp on average.

The amounts of malic acid decreased gradually from 180 to 260 DAA in Eureka lemon and the cybrid but remained relatively constant in Willow leaf mandarin (Figure 2b). The
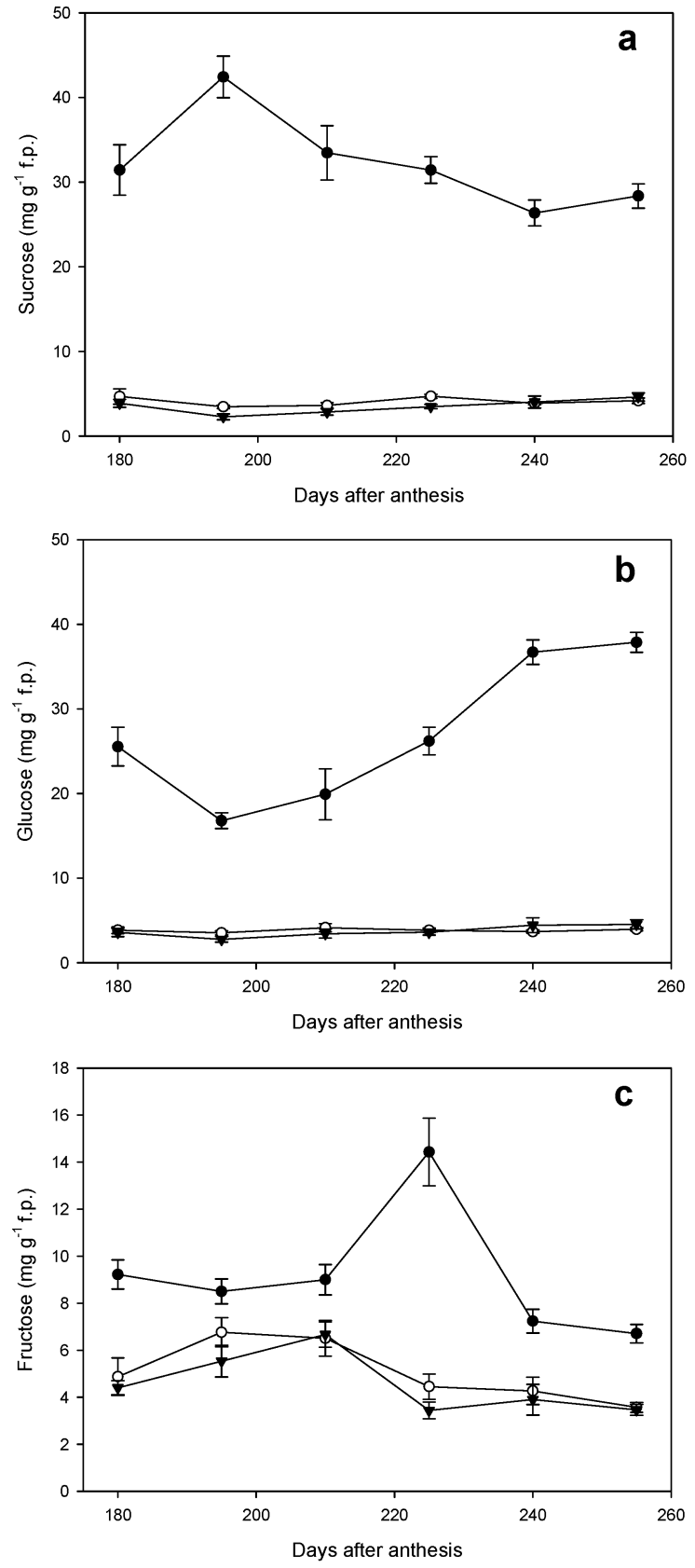

$\longrightarrow$ Willow leaf-O- WLM + EUR $\rightarrow-$ E. Lemon

Figure 3. Sugar levels in fruit pulp during the mature stage of Willow

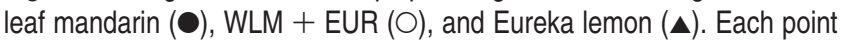
on the graph shows the mean and standard error of three biological replicates.

cybrid displayed the highest amounts of malic acid $(5.48 \mathrm{mg}$ $\mathrm{g}^{-1} \mathrm{fp}$ ) followed by Eureka lemon (4.63 $\mathrm{mg} \mathrm{g}^{-1} \mathrm{fp}$ ) and Willow leaf $\left(2.10 \mathrm{mg} \mathrm{g}^{-1} \mathrm{fp}\right)$. The amounts of ascorbic acid in fruits of Willow leaf mandarin decreased gradually from $0.41 \mathrm{mg} \mathrm{g}^{-1}$ $\mathrm{fp}$ and reached $0 \mathrm{mg} \mathrm{g}^{-1} \mathrm{fp}$ at $260 \mathrm{DAA}$. The cybrid and Eureka lemon displayed the same changing pattern with a constant level of ascorbic acid, 0.48 and $0.40 \mathrm{mg} \mathrm{g}^{-1} \mathrm{fp}$, respectively (Figure 2c).

Sugar Contents at Fruit Maturity. Three major sugars (sucrose, glucose, and fructose) were identified in pulp of the three genotypes. Willow leaf mandarin presented fruits with much higher sugar contents than Eureka lemon and WLM + EUR (Figure 3). The concentration of sucrose in fruit pulp of Willow leaf mandarin decreased with maturity from 42.43 to 
Table 1. Carotenoid Contents $(\mathrm{mg} / \mathrm{L})^{a}$

\begin{tabular}{lcccccc}
\hline genotypes & phytoene & phytofluene & $\beta$-carotene & $\beta$-cryptoxanthin & lutein & zeaxanthin \\
\hline Willow leaf & $1.62 \pm 0.13$ & $2.78 \pm 0.21$ & $1.47 \pm 0.12 \mathrm{a}$ & $17.66 \pm 1.15 \mathrm{a}$ & $0.96 \pm 0.05$ & $1.29 \pm 0.03$ \\
WLM + EUR & & & $0.07 \pm 0.01 \mathrm{~b}$ & $0.20 \pm 0.01 \mathrm{~b}$ & & $3.74 \pm 0.15$ \\
Eureka lemon & & & $0.11 \pm 0.01 \mathrm{~b}$ & $0.34 \pm 0.02 \mathrm{~b}$ & & \\
\end{tabular}

${ }^{a}$ Different letters in the same column indicate significant differences in carotenoid contents ( $\alpha=0.05 \%$ ).

$28.37 \mathrm{mg} \mathrm{g}^{-1} \mathrm{fp}$, whereas in WLM + EUR and Eureka lemon, it remained relatively constant at $3 \mathrm{mg} \mathrm{g}^{-1} \mathrm{fp}$ (Figure 3a). Willow leaf mandarin showed an increase in glucose from 195 DAA (16.78 $\mathrm{mg} \mathrm{g}^{-1} \mathrm{fp}$ ) until the end (37.87 $\left.\mathrm{mg} \mathrm{g}^{-1} \mathrm{fp}\right)$, whereas WLM + EUR and Eureka lemon shared low values ( $3 \mathrm{mg} \mathrm{g}^{-1} \mathrm{fp}$ ) of glucose (Figure 3b). The difference in fructose in Willow Leaf and acid fruits was low compared to the differences in sucrose and glucose (Figure 3c).

Carotenoid Composition and Concentration. Seven carotenoids were isolated and quantified in the pulp (Table 1). Willow leaf mandarin was characterized by a complex carotenoid composition. Xanthophylls were predominant and $\beta$-cryptoxanthin, violaxanthin zeaxanthin, and lutein accounted for $80 \%$ of the total carotenoid content. Linear carotenes were also detected, such as phytoene $(1.62 \pm 0.13$ $\left.\mathrm{mg} \mathrm{L}^{-1}\right)$ and phytofluene $\left(2.78 \pm 0.21 \mathrm{mg} \mathrm{L}^{-1}\right)$. The mandarin parent accumulated large amounts of carotenoid and very large quantities of $\beta$-cryptoxanthin $(17.66 \pm 1.15$ $\left.\mathrm{mg} \mathrm{L}^{-1}\right)$. Conversely, in Eureka lemon and the cybrid, only very low concentrations of $\beta$-carotene and $\beta$-cryptoxanthin $\left(\beta\right.$-carotene $+\beta$-cryptoxanthin $\left.\leq 0.5 \mathrm{mg} \mathrm{L}^{-1}\right)$ were detected. In addition, no significant quantitative difference was found between the cybrid and the lemon parent.

\section{DISCUSSION}

Genetic analyses revealed that the cybrid represents a lemon genome with Willow leaf mitochondria. This new genetic constitution may affect the composition of components involved in fruit quality because lemon and mandarin are different fruits. The parents displayed two different titratable acid profiles. Eureka lemon had an acid profile, while the profile of Willow leaf mandarin was less acidic. The values obtained for Eureka lemon $\left(0.8 \mathrm{meq}^{-1} \mathrm{fp}\right)$ are in agreement with those generally reported in the literature for lemon varieties $(35,38)$. The cybrid had an enhanced lemon profile, with 0.94 meq $\mathrm{g}^{-1} \mathrm{fp}$. Results suggest that the change from lemon mitochondria into mandarin mitochondria had an effect on acidity. In citrus juice, titratable acidity is known to be largely due to citric acid $(35,39)$, which is the major organic acid at the mature stage. In terms of amounts, WLM + EUR also displayed higher levels of citric acid than Eureka lemon (Figure 2). These results suggest that the cybrid improved the ability of Eureka lemon to produce high levels of citric acid. However, it is important to note that protoplast regenerated via somatic embryogenesis can induce genetic variation that may be responsible for minor phenotypic change (40). The citric acid cycle takes place in the matrix of the mitochondria of juice cells (41). We can thus suppose that the new mitochondria are the cause of the super production of organic acids in cybrid fruit pulp. It is interesting to note that the mitochondria originated from mandarin, which accumulates lower levels of organic acids. Mitochondria could play a machinery role, producing organic acids as a function of the glycolytic sugar substrate.

The concentration of ascorbic acid was seen to decrease in Willow leaf during the mature stage, as in the juice of oranges and grapefruit (42), whereas lemons undergo an increase in ascorbic acid (43), which was conserved in the cybrid. It has previously been demonstrated that the ascorbic acid biosynthetic pathway is cytosolic except for the last step located on the inner mitochondrial membrane (44). The cybrid conserved cytosol from lemon, which explains why the cybrid accumulated ascorbic acid at maturity.

Lemons and mandarins display significant differences in their characteristic sugar storage patterns. Lemons contain little sugar and high amounts of organic acids (35), in contrast to mandarins, which contain high amounts of sugar and less organic acids. Sugars are synthesized in the cytosol. We observed that, similar to Eureka lemon, the cybrid had low sugar contents and high organic acid contents. This behavior can be explained by the presence of the lemon cytosol in the cybrid cells.

The two parents presented different carotenoid compositions (Table 1). Willow leaf mandarin was characterized by high amounts of xanthophylls and the massive accumulation of $\beta$-cryptoxanthin, whereas Eureka lemon was very poor in carotenoids. These results are in agreement with those of Fanciullino et al. (37) and Matsumoto et al. (45) on carotenoid compositions of mandarin and lemon varieties. In the works of these authors, mandarins were classified as violaxanthin- and $\beta$-cryptoxanthin-abundant or as violaxanthin-, phytoene-, and $\beta$-cryptoxanthin-abundant varieties, while lemons were classified as carotenoid-poor varieties. The cybrid, which inherited its nucleus and chloroplasts from the lemon parent, had a lemon carotenoid profile. This result was foreseeable because the cybrid fruits displayed the same pomological traits as those of Eureka lemon, particularly color. In addition, carotenoids are synthesized in plastids (chloroplasts or chromoplasts), and the enzymes of the carotenoid biosynthetic pathway are nuclear-encoded $(25,26)$. Atienza et al. (46) underlined the importance of cytoplasm in determining endosperm carotenoid content in bread wheat. Our results showed that in citrus fruit, mitochondria do not affect carotenoid accumulation. Carotenoid accumulation is influenced by both the level of activity of the carotenoid biosynthetic genes and the presence of carotenoid-storing structures (47).

Our results suggest that the main genetic information for the biosynthesis of compounds involved in citrus fruit quality are contained in the nucleus and that the expression of these nuclear genes is not at all or only very slightly affected by interactions with the mitochondrial genome. Among carotenoid, sugar, and organic acid contents, only organic acids showed minor differences. The quantitative differences between the cybrid and the lemon parent with respect to organic acids could originate in a nucleo-cytoplasmic interaction. Gene expression patterns between several mitochondrial cybrids and their nucleus parent now need to be compared to test this hypothesis. From our results and the results of Fanciullino et al. (15), we conclude that cybridization should be used in citrus as a strategy to breed specific traits associated with mitochondrial genomes, such as male sterility, without affecting the main organoleptic and nutritional qualities. 


\section{LITERATURE CITED}

(1) Khan, I. A.; Kender, W. J. Citrus breeding: Introduction and objectives. In Citrus Genetics, Breeding and Biotechnology; Khan, I. A., Ed.; Cabi Publishing: Oxfordshire, U.K., 2007; pp 1-8.

(2) Nicolosi, E.; Deng, Z. N.; Gentile, A.; Malfa, S. 1.; Continella, G.; Tribulato, E. Citrus phylogeny and genetic origin of important species as investigated by molecular markers. Theor. Appl. Genet. 2000, 1001155-1166.

(3) Ollitrault, P.; Luro, F. Citrus. In Tropical Plant Breeding; Charrier, A., Jacquot, M., Hamon, S., Nicolas D., Eds.; Science Publishers, Inc.: U.S.A., 2001; pp 55-77.

(4) Spangenberg, G.; Freydl, E.; Osusky, M.; Nagel, J.; Potrykus, I. Organelle transfer by microfusion of defined protoplast-cytoplast pairs. Theor. Appl. Genet. 1991, 81, 477-486.

(5) Zubko, M. K.; Zubko, E. I.; Patskovsky, Y. V.; Khvedynich, O. A.; Fisahn, J.; Gleba, Y. Y.; Schieder, O. Novel "homeotic" CMS patterns generated in Nicotiana via cybridization with Hyoscyamus and Scopolia. J. Exp. Bot. 199647, 1101-1110.

(6) Guo, W. W.; Prasad, D.; Cheng, Y. J.; Serrano, P.; Deng, X. X.; Grosser, J. W. Targeted cybridization in citrus: Transfer of satsuma cytoplasm to seedy cultivars for potential seedlessness. Plant Cell Rep. 2004, 22, 752-758.

(7) Li, Y. G.; Tanner, G. J.; Delves, A. C.; Larkin, P. J. Asymmetric somatic hybrid plants between Medicago sativa L. (alfalfa, lucerne) and Onobrychis viciifolia Scop. (sainfoin). Theor. Appl. Genet. 1993, 87, 455-463.

(8) Vardi, A.; Breiman, A.; Galun, E. Citrus cybrids: Production by donor-recipient protoplast-fusion and verification by mitochondrial-DNA restriction profiles. Theor. Appl. Genet. 1987, 75, 5158.

(9) Grosser, J. W.; Ollitrault, P.; Olivares-Fuster, O. Somatic hybridization in citrus: An effective tool to facilitate variety improvement. In Vitro Cell. Dev. Biol.: Plant 2000, 36, 434-449.

(10) Olivares-Fuster, O.; Duran-Vila, N.; Navarro, L. Electrochemical protoplast fusion in citrus. Plant Cell Rep. 2005, 24, 112-119.

(11) Ollitrault, P.; Guo, W. W.; Grosser, J. W. Somatic hybridization. In Citrus Genetics, Breeding and Biotechnology; Khan, I. A., Ed.; Cabi Publishing: Oxfordshire, U.K., 2007; pp 235-260.

(12) Xu, X. Y.; Liu, J. H.; Deng, X. X. Isolation of cytoplasts from satsuma mandarin (Citrus unshiu Marc.) and production of alloplasmic hybrid calluses via cytoplast-protoplast fusion. Plant Cell Rep. 2006, 25, 533-539.

(13) Cabasson, C. M.; Luro, F.; Ollitrault, P.; Grosser, J. W. Non-random inheritance of mitochondrial genomes in citrus hybrids produced by protoplast fusion. Plant Cell Rep. 2001, 20, 604-609.

(14) Moreira, C. D.; Chase, C. D.; Gmitter, F. G., Jr.; Grosser, J. W. Transmission of organelle genomes in citrus somatic hybrids. Plant Cell, Tissue Organ Cult. 2000, 61, 165-168.

(15) Pelletier, G.; Primard, C.; Vedel, F.; Chetrt, P.; Remy, R.; Rousselle, P.; Renard, M. Intergeneric cytoplasmic hybridization in Cruciferae by protoplast fusion. Mol. Gen. Genet. 1983, 191, 244-250.

(16) Barsby, T. L.; Yarrow, S. A.; Kemble, R. J.; Grant, I. The transfer of cytoplasmic male sterility to winter-type oilseed rape (Brassica napus L.) by protoplast fusion. Plant Sci. 1987, 53, 243-248.

(17) Thomzik, J. E.; Hain, R. Transfer and segregation of triazine tolerant chloroplasts in Brassica napus L. Theor. Appl. Genet. 1988, 76, 165-171.

(18) Varotto, S.; Nenz, E.; Lucchin, M.; Parrini, P. Production of asymmetric somatic hybrid plants between Cichorium intybus L. and Helianthus annuus L. Theor. Appl. Genet. 2001, 102, 950-956.

(19) Pelletier, G.; Budar, F. The molecular biology of cytoplasmically inherited male sterility and prospects for its engineering. Curr. Opin. Biotechnol. 2007, 18, 121-125.

(20) Yarrow, S. A.; Burnett, L. A.; Wildeman, R. P.; Kemble, R. J. The transfer of "Polima" cytoplasmic male sterility from oilseed rape (Brassica napus) to broccoli (B. oleracea) by protoplast fusion. Plant Cell Rep. 1990, 9, 185-188.
(21) Fitter, J. T.; Thomas, M. R.; Niu, C.; Rose, R. J. Investigation of Nicotiana tabacum $(+)$ N. suaveolens cybrids with carpelloid stamens. J. Plant Physiol. 2005, 162, 225-235.

(22) Chang, C.; Uesugi, R.; Hondo, K.; Kakihara, F.; Kato, M. The effect of the cytoplasms of Brassica napus and B. juncea on some characteristics of $B$. carinata, including flower morphology. Euphytica 2007, 158, 261-270.

(23) Fanciullino, A. L.; Gancel, A. L.; Froelicher, Y.; Luro, F.; Ollitrault, P.; Brillouet, J. M. Effects of nucleo-cytoplasmic interactions on leaf volatile compounds from citrus somatic diploid hybrids. J. Agric. Food Chem. 200553, 4517-4523.

(24) Hirschberg, J. Carotenoid biosynthesis in flowering plants. Curr. Opin. Plant Biol. 2001, 4, 210-218.

(25) Gallagher, C. E.; Matthews, P. D.; Li, F. Q.; Wurtzel, E. T. Gene duplication in the carotenoid biosynthetic pathway preceded evolution of the grasses. Plant Physiol. 2004, 135, 1776-1783.

(26) Taylor, M.; Ramsay, G. Carotenoid biosynthesis in plant storage organs: Recent advances and prospects for improving plant food quality. Physiol. Plant. 2005124, 143-151.

(27) Ollitrault, P.; Dambier, D.; Froelicher, Y.; Carreel, F.; d'Hont, A.; Luro, F.; Bruyere, S.; Cabasson, C.; Lotfy, S.; Joumaa, A.; Vanel, F.; Maddi, F.; Treanton, K.; Grisoni, M. Somatic hybridisation potential for citrus germplasm utilization. Cahiers Agric. 2000, 9, 223-236.

(28) Mouhaya, W.; Bassene, J. B.; Costantino, G.; Ollitrault, P.; Luro, F.; Risterucci, A. M.; Morillon, R.; Froelicher, Y. Mitochondrial PCR markers reveal genetic diversity in Citrus and related genera. Plant Cell Rep., manuscript submitted.

(29) Cercos, M.; Soler, G.; Iglesias, D. J.; Gadea, J.; Forment, J.; Talon, M. Global analysis of gene expression during development and ripening of citrus fruit flesh. A proposed mechanism for citric acid utilization. Plant Mol. Biol. 2006, 62, 513-527.

(30) Ollitrault, P.; Dambier, D.; Luro, F.; Duperray, C. Nuclear genome size variations in citrus. Fruits 1994, 49, 390-393, 475-476.

(31) Froelicher, Y.; Dambier, D.; Bassene, J. B.; Costantino, G.; Lotfy, S.; Didout, C.; Beaumont, V.; Brottier, P.; Risterucci, A. M.; Luro, F.; Ollitrault, P. Characterization of microsatellite markers in mandarin orange (Citrus reticulata Blanco). Mol. Ecol. Res. 2008, 8, 119-122.

(32) Cheng, Y.; Vicente, M. C. d.; Meng, H.; Guo, W.; Tao, N.; Deng, $\mathrm{X}$. A set of primers for analyzing chloroplast DNA diversity in Citrus and related genera. Tree Physiol. 2005, 25, 661-672.

(33) Lotfy, S.; Luro, F.; Carreel, F.; Froelicher, Y.; Rist, D.; Ollitrault, P. Application of cleaved amplified polymorphic sequence method for analysis of cytoplasmic genome among Aurantioideae intergeneric somatic hybrids. J. Am. Soc. Hortic. Sci. 2003, 128, 225-230.

(34) Bain, J. M. Morphological, anatomical and physiological changes in the developing fruit of Valencia orange, Citrus sinensis (L.) Osbeck. Aust. J. Bot. 1958, 6, 1-24.

(35) Albertini, M. V.; Carcouet, E.; Pailly, O.; Gambotti, C.; Luro, F.; Berti, L. Changes in organic acids and sugars during early stages of development of acidic and acidless citrus fruit. J. Agric. Food Chem. 2006, 54, 8335-8339.

(36) Dhuique-Mayer, C.; Caris-Veyrat, C.; Ollitrault, P.; Curk, F.; Amiot, M. J. Varietal and interspecific influence on micronutrient contents in citrus from the Mediterranean area. J. Agric. Food Chem. 2005, 53, 2140-2145.

(37) Fanciullino, A. L.; Dhuique-Mayer, C.; Luro, F.; Casanova, J.; Morillon, R.; Ollitrault, P. Carotenoid diversity in cultivated citrus is highly influenced by genetic factors. J. Agric. Food Chem. 2006, 54, 4397-4406.

(38) Sadka, A.; Dahan, E.; Cohen, L.; Marsh, K. B. Aconitase activity and expression during the development of lemon fruit. Physiol. Plant. 2000, 108, 255-262.

(39) Rasmussen, G. K. Seasonal changes in organic acid content of Valencia orange fruit in Florida. J. Am. Soc. Hortic. Sci. 1963, 84, 181-187.

(40) Orbovic, V.; Calovic, M.; Viloria, Z.; Nielsen, B.; Gmitter, F. G., Jr.; Castle, W. S.; Grosser, J. W. Analysis of genetic variability in various tissue culture-derived lemon plant populations using RAPD and flow cytometry. Euphytica 2008, 161, 329-335. 
(41) Tucker, G. A. Introduction. In Biochemistry of Fruit Ripening; Seymour, G., Taylor, J., Tucker, G., Eds.; Chapman and Hall: London, U.K., 1993; pp 1-37.

(42) Robertson, G. L.; Nisperos, M. O. Changes in the chemical constituents of New Zealand grapefruit during maturation. Food Chem. 1983, 11, 167-174.

(43) Bartholomew, E. T.; Sinclair, W. B. The Lemon Fruit: Its Composition, Physiology, and Products; University of California Press: Berkeley, CA, 1951; p 163.

(44) Smirnoff, N. Ascorbic acid: Metabolism and functions of a multifacetted molecule. Curr. Opin. Plant Biol. 20003, 229-235.

(45) Matsumoto, H.; Ikoma, Y.; Kato, M.; Kuniga, T.; Nakajima, N.; Yoshida, T. Quantification of carotenoids in citrus fruit by LCMS and comparison of patterns of seasonal changes for caro- tenoids among citrus varieties. J. Agric. Food Chem. 2007, 55 , 2356-2368.

(46) Atienza, S. G.; Martin, A.; Pecchioni, N.; Platani, C.; Cattivelli, L. The nuclear-cytoplasmic interaction controls carotenoid content in wheat. Euphytica 2008, 159, 325-331.

(47) Howitt, C. A.; Pogson, B. J. Carotenoid accumulation and function in seeds and non-green tissues. Plant, Cell Environ. 2006, 29, $435-445$.

Received for review April 18, 2008. Revised manuscript received July 11, 2008. Accepted July 21, 2008. We thank the Collectivité Territoriale de Corse for granting this study.

JF801233M 